

\section{Centro de estudios del niño Una experiencia de educacion especial}

\section{Margoth Acosta Leal}

Integrante del equipo de investigación conformado por Hilda Rubio, José Daza y William Perdomo

\section{Fundación en el IED \\ La Palestina \\ Centro de Estudios del Niño}

Este documento da cuenta de dos elementos explorados: la indiferencia de los colegios oficiales de preservar sus archivos, y los recuerdos de docentes y vecinos a la Institución. Por último, plantea unas reflexiones finales.

\section{Recopilación de información}

Recoger la historia de las instituciones educativas oficiales del Distrito es una tarea titánica, pues en su mayor parte las fuentes son orales y el material documental, fílmico o fotográfico es casi inexistente.

En la indagación por las huellas de la Institución Educativa Centro de Estudios del Niño -al parecer, una de las primeras que en Bogotá se hizo cargo de la educación para niños especiales-, se partió de la narración oral de dos docentes y de una vecina del sector, y se tuvieron en cuenta datos obtenidos en algunos trabajos de grado realizados por estudiantes de Licenciatura en Básica Primaria con énfasis en Estética de Uniminuto, en donde, de manera fragmentada y en algunos casos contradictoria, dan cuenta de lo ocurrido durante su fundación. En la Institución no hay material escrito, fílmico ni fotográfico que permita corroborar las versiones orales ni mucho menos describir el trabajo que el Centro realizó con niños discapacitados; las huellas se han borrado.

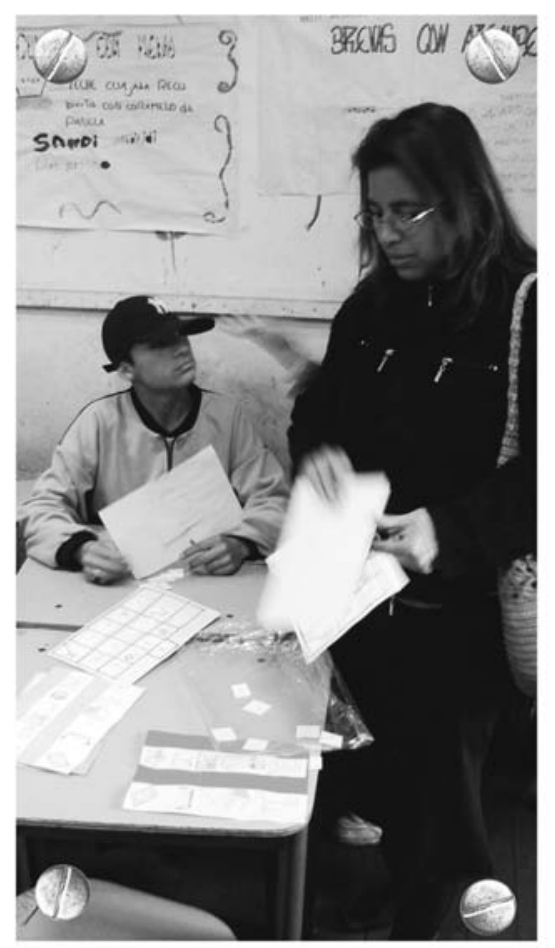


La profesora Martha Cortés -quien entró a laborar a la Institución en 1987-, dijo, basada en testimonios de Rosalba de Pulido, ya fallecida, que el Centro empezó a funcionar en 1952, en los terrenos que fueron donados por el expresidente Alfonso López Pumarejo, mediante un convenio entre la Secretaría de Salud y la Secretaría de Gobierno de Bogotá. El propósito del Centro era albergar niños con problemas de conducta y con problemas de aprendizaje, pero sólo funcionaba la jornada de la mañana, pues en la tarde el número de estudiantes se consideró insuficiente.

Según ella, en esa época funcionaba un equipo conformado por médicos, psiquiatras, trabajadoras sociales, psicopedagogas y docentes, que de manera integrada atendían niños con discapacidad, quienes por vergüenza social, eran escondidos en sus casas 0 abandonados. Con el propósito de lograr su recuperación, el Centro contaba con talleres de carpintería y de modistería; además había un internado, que permitía el aprendizaje de un oficio y el desarrollo de sus capacidades físicas y mentales, lo cual se sumaba al cuidado permanente de los niños, atendidos en grupos de trabajo de ocho a diez como

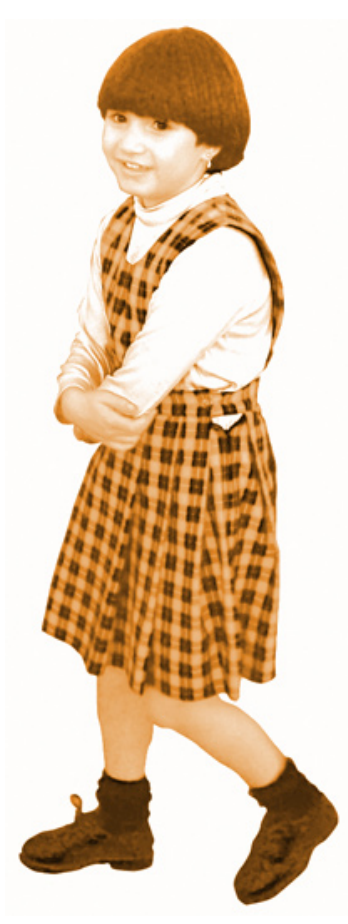

máximo. El primer director fue el doctor Ramírez, psiquiatra de profesión, y el primer profesor Teófilo Any. Los primeros docentes nombrados allí por el Estado fueron Elvira de Cuervo y Sixto Riascos.

Posiblemente, la falta de presupuesto fue una de las principales razones para terminar el proyecto, pues mantener el equipo, los talleres y el internado, además de la afluencia cada vez mayor de niños, hacía que fuera insostenible; además, los resultados no eran susceptibles de ser evidenciados en registros de seguimiento. Esta situación podría explicar la inexistencia de documentación que dé cuenta de ello.

\section{Recuerdos de un maestro pensionado}

El profesor Reinaldo Cubillos laboró en la Institución desde 1969 hasta 1998, además de confirmar la versión de la profesora Martha Cortés, comenta que el Centro provino de una "rendición de cuentas que hizo Alberto Lleras Camargo por la distribución inadecuada de la Reforma Agraria contemplada en la ley 200 de 1936". La 'donación' correspondía a $17.000 \mathrm{~m}^{2}$ que incluía la laguna de Bellavista II, hoy humedal de Santa María del Lago. 
En 1947 existía la casa de cuidanderos en la parte sur del predio; hacia el fondo estaba la casa de campo de los López Pumarejo. En 1952, a partir de lo existente, se construyó un pabellón donde funcionaba el internado con los dormitorios, enseguida estaba un salón de clases, la cocina el restaurante y los sanitarios. Tiempo después, debido a la demanda, la casa de los cuidanderos se acondicionó para salones.

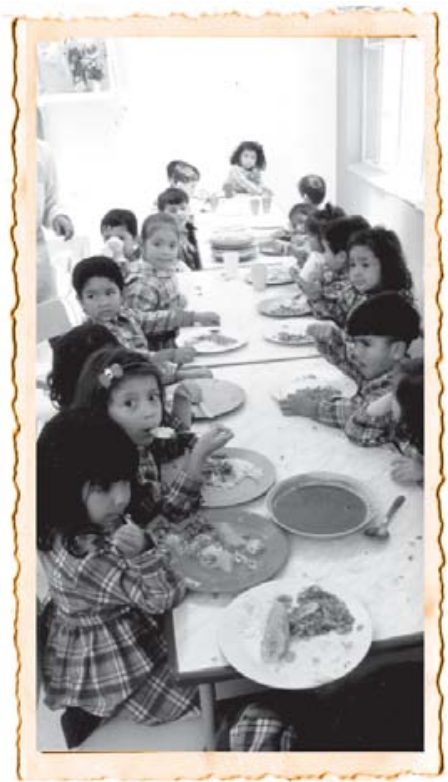

Aparte del internado, funcionaba una granja autosuficiente con cultivos propios de la región y animales como gansos, vacas, patos y conejos. El trabajo en la granja era un instrumento de rehabilitación de los niños con problemas de conducta.
En 1962, el Centro empezó a funcionar en la jornada de la tarde para niños regulares, pues en la mañana atendían a niños especiales. De esta manera se trabajó hasta 1974 cuando, por orden de Elvira Guarín de Vizcaya, funcionaria de la Secretaría de Educación, se dio por terminado el proyecto, pues no funcionaba como se esperaba y porque en ese sector faltaban escuelas para niños regulares. En ese momento el doctor Ramírez se dedicó a formar maestros para trabajar con niños con problemas de conducta y de aprendizaje.

\section{Remembranzas de una vecina}

En conversaciones con la señora María Ignacia Rodríguez, vecina de la Institución y habitante del sector desde hace 40 años, además de confirmar otras versiones sobre la fundación, recuerda de manera vaga que:

esta institución comenzó a funcionar [...] con niños infradotados. En el año 1972 se cerró como educación especial y desde 1974 funciona como escuela en las dos jornadas laborando actualmente sin interrupción
Dice que es muy difícil dar otros detalles, pues en 1972 el sector estaba rodeado de lotes baldíos, era un sector solitario y el único transporte era el trolley-bus, cuya última estación de parqueo quedaba en inmediaciones del Centro. Además, afirma que había cierto ocultamiento hacia la comunidad del tipo de trabajo que se realizaba, pues trabajar con niños discapacitados era tema vedado y extraño para la gente común y corriente.

\section{La memoria escrita}

En la revisión efectuada a los trabajos de grado elaborados por los estudiantes de la Facultad de Educación de la Corporación Universitaria Minuto de Dios, encontramos que:

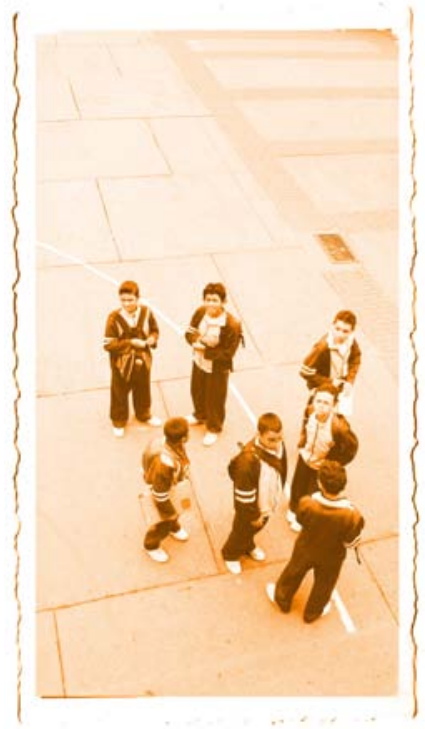


El Centro de Estudios del Niño antes de ser fundada, era la casa de campo de Alfonso López Pumarejo, quien la cedió para un centro de atención de gamines. Estaba dotada de talleres de carpintería, modistería e internado. Debido al mal uso y al trato que se le dio al Centro se fue deteriorando para luego más tarde ser destruido por un incendio. Luego se fundó una escuela para atender niños con problemas de aprendizaje. $Y$ finalmente se funda la escuela formal Centro de Estudios del Niño que actualmente funciona ofreciendo a los niños una oportunidad para estudiar y salir adelante.

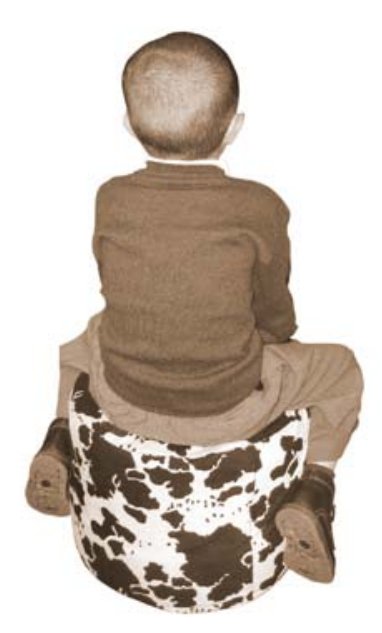

Se inició con 16 cursos en la mañana y 16 en la tarde, en una época en que había súper población en esta zona y mucha demanda de escuela primaria. Hasta 1991 la Institución trabajó con las dos jornadas pero luego de una reunión a finales del mismo año se decidió cerrar la jornada de la tarde y se abrió la jornada alterna $^{1}$

En dos trabajos de grado realizados en 1996 y 1997, se afirma que:

hasta 1990 la Institución trabaja con las dos jornadas, pero luego de una reunión a finales del mismo año se decidido terminar con la jornada de la tarde ya que la población estudiantil había disminuido notablemente. Hasta el año de 1990 la directora era aura María Castro de Perlaza, actualmente es dirigida por Rosalba Ontibón

\section{Algunas reflexiones}

Las diversas versiones sobre la fundación de la Institución, indican que tampoco es posible responder a las preguntas: ¿de dónde partió la idea inicial de atender niños con necesidades especiales?, ¿en qué momento se decidió acabar con este servicio y por qué?, ¿realmente se atendió a niños especiales?

Hago un llamado a las instituciones educativas para que reconozcan la importancia de preservar archivos que permitan la recuperación histórica de los caminos que cada una recorre en su trasegar cotidiano, pues la memoria y la historia permiten comprender los aciertos y los desaciertos, desarrollar el sentido de pertenencia y mostrar el sello particular que la distingue y la hace única frente a otras similares a ella. $₫$ e y c

1 El juego: estrategia metodológica para cultivar el gusto por la lectura y la escritura en niños con edades de 5 y 6 años. Tesis de grado, Bogotá: Uniminuto, 1997. 


\section{El museo de las escuelas problemas teórico-metodológicos}

\section{María Cristina Linares}

Licenciada en Ciencias de la Educación. Magíster en

Política y Gestión de la Educación; actualmente doctoranda en la Universidad Nacional de Luján. Argentina.

\section{El Museo de las escuelas en Argentina}

En poco más de tres años de la implementación del Museo de las escuelas, varios temas han surgido como problemáticas y muchos de ellos continúan en discusión. Las motivaciones que se desprenden de los actuales proyectos de museos de la educación, parten de la necesidad de documentar e interpretar a la escuela en el pasado. Esta postura se relaciona con la decadencia de un modelo de escuela nacido en el siglo XIX y del cual sus huellas comenzaron a borrarse a partir de la década de 1960.

Por un lado, se intenta guardar y rescatar la 'memoria' de lo que puede llegar a borrarse, como objetos, ideas y prácticas y, por otro, se propone elaborar una visión más o menos crítica del pasado.
En 1998, la Cátedra de historia social de la educación - del Departamento de educación de la Universidad Nacional de Luján- se propuso, como extensión del proyecto de investigación de la Historia de la enseñanza de la lectura y escritura en Argentina (HISTELEAl), la creación de un Museo de la escuela para recuperar todo tipo de utilería didáctica: fotografías, testimonios orales, etc., y preservarlos de su desaparición. Los primeros objetos de la colección fueron expuestos en 1999 y en 2000.

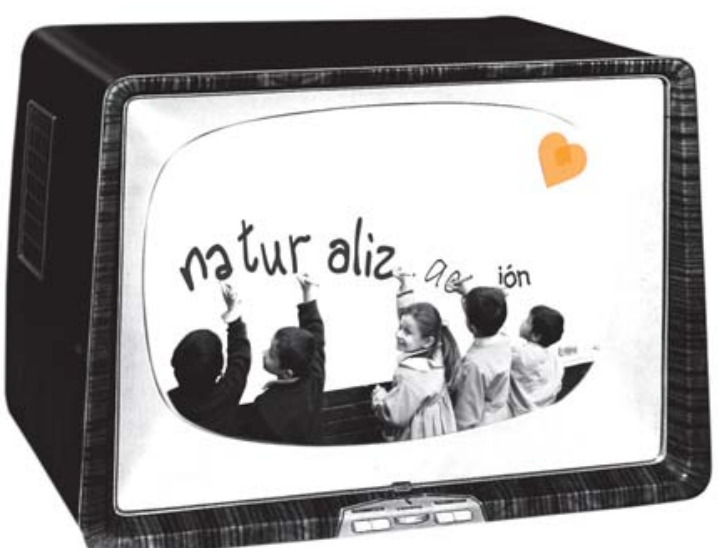


Durante 2001, docentes de la Dirección Área Educación Nivel Inicial de la Secretaría de Educación del Gobierno de Buenos Aires, organizaron la muestra de imágenes, textos, luchas e historias sobre el Jardín de Infantes. El propósito de esta muestra, fue recuperar huellas de la vida cotidiana de esta institución a lo largo de varias décadas de la historia de la educación. La etapa de recopilación estuvo centrada en los años 1870, 1937 y 1950, los cuales fueron determinantes para el surgimiento del Nivel Inicial en el país y en la ciudad.

Ambas colecciones pasaron a integrar el acervo del Museo de las escuelas que la Secretaría de Educación del Gobierno de la ciudad y la Universidad Nacional de Luján inauguraron el 10 de septiembre de 2002. La actual exposición, Lo que el borrador no se llevó, se encuentra en el galpón del Ministerio de Educación, Ciencia y Tecnología de la Nación de Buenos Aires. Uno de los propósitos del Museo de las escuelas, es que los visitantes se apropien de objetos, ideas y prácticas escolares de modo que se articulen con la memoria y la actualidad escolar de los mismos, para que se generen nuevas lecturas de lo 'heredado' y se desarrolle una visión socio-histórica crítica de la educación para comprender el presente e imaginar lo por venir. En este sentido, vemos la 'historia social de la educación', como el campo de los modos, medios y relaciones sociales de producción, transmisión, apropiación y distribución de saberes. Estos fenómenos suceden en un espacio y en un tiempo determinado y en articulación con otras dimensiones contextuales. Nuestra intención no es desentendernos de los 'condicionamientos' de los componentes estructurales de la sociedad, lo que sugiere una relación dialéctica entre un suceso discursivo particular y las situaciones, instituciones y estructuras sociales que lo enmarcan, lo moldean y a la vez le dan forma. "La búsqueda de comprensión implica pensar en una dialéctica metodológica de interacción sujeto-objeto que permita la comprensión desde dentro de los fenómenos históricos sociales, humanos" (Sirvent, 1999:14).

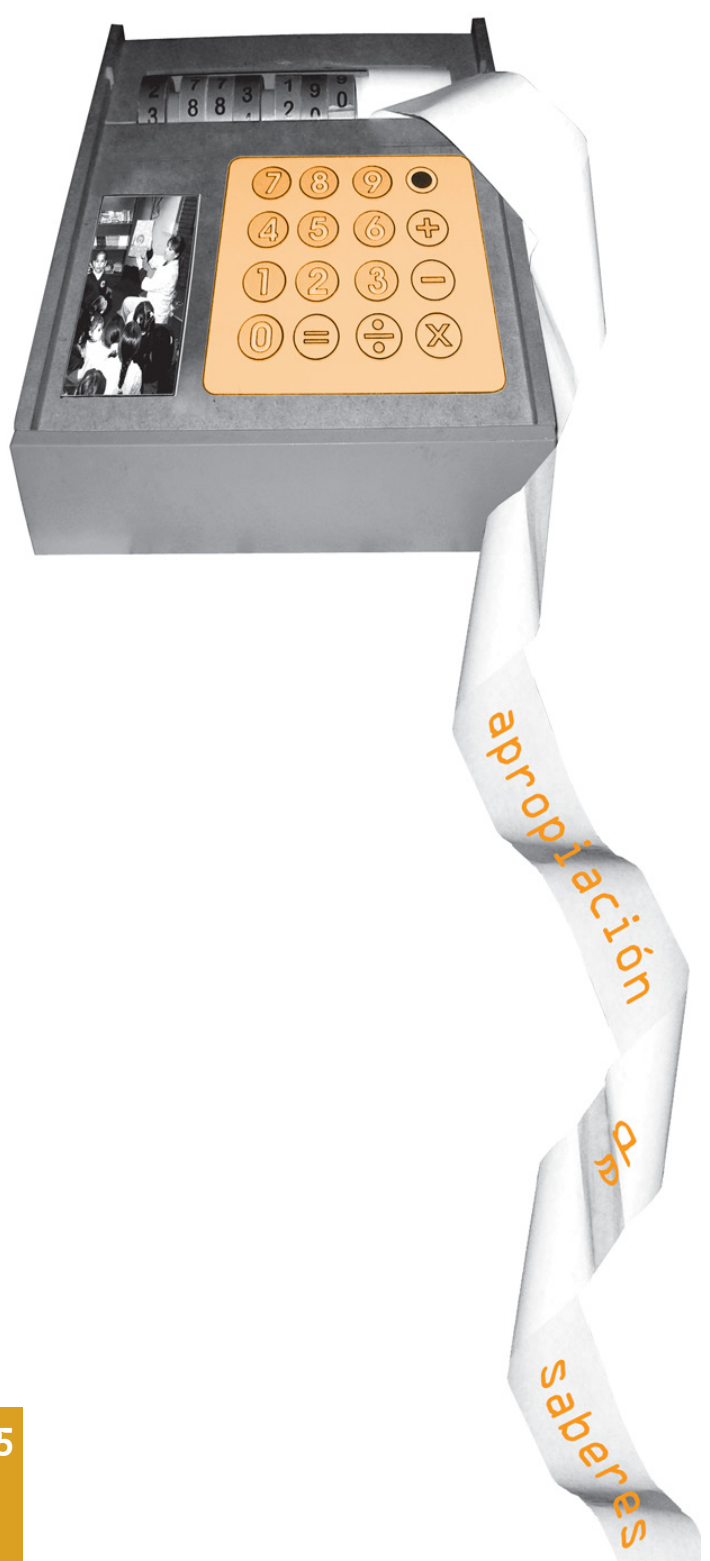


Comprendemos la institución escolar como un producto histórico particular de las sociedades occidentales, que puede datar del siglo XVI. Intentamos mostrar su articulación al proceso de construcción de la sociedad moderna con el surgimiento del modo capitalista de producción y la construcción de los Estados Nacionales, así como a los procesos de su imposición/adopción en Argentina.

\section{Problemas teórico-metodológicos Obstáculo epistemológico}

Un primer problema se presenta cuando se trabaja desde la historia de la educación. Todos los visitantes del Museo2 han vivido o están viviendo la experiencia escolar, por lo que su primer acercamiento se relaciona directamente con sus vivencias. En alguna medida, sus recuerdos funcionan como un obstáculo epistemológico para producir otras interpretaciones: un pre-juicio, una mirada particular que los relaciona de manera singular con la muestra. Esto representa a la exposición un doble trabajo: des-estructurar produciendo, en lo posible, un 'choque de ideas' para luego admitir otras lecturas $y$, en muchos casos, las lecturas de los otros y las lecturas desde la historia. Pero para que ello suceda, resulta imperioso 'desnaturalizar' la escuela. La 'desnaturalización' de los fenómenos sociales es una tarea fundamental de las ciencias sociales, pues la 'naturalización' oculta el carácter construido de los mismos. Podemos decir que 'desnaturalizar' equivale a poner de manifiesto su proceso de construcción. Por otra parte, y contrario a las ideas implícitas en la noción del progreso, el cambio histórico no es una sucesión de etapas en donde la anterior es descartada en favor de una nueva, sino que existe una suerte de acumulación geológica de modificaciones que configuran un perfil en donde lo 'viejo' perdura y opera sobre lo 'nuevo'.

\footnotetext{
2 Lo mismo sucede con otro tipo de experiencias como las cátedras
} de Historia de la educación, publicaciones, etc.

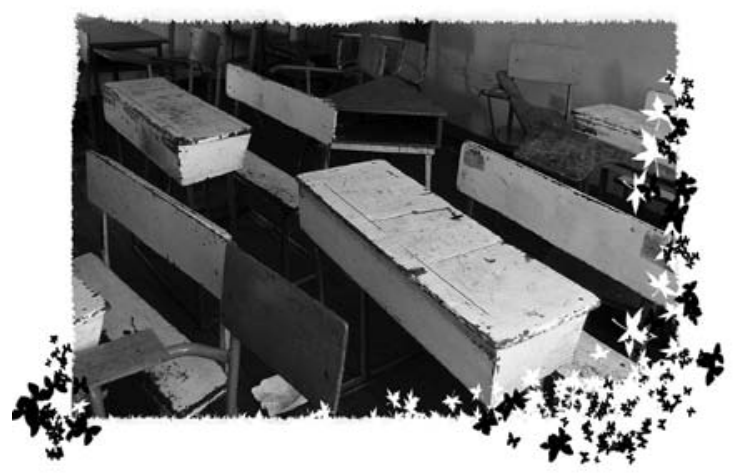

La 'naturalización' se apoya en el supuesto de que todo lo que se aparta de una línea recta ascendente o descendente, es desechable o impensable. En este sentido, sólo cabe la detención del progreso, del 'avance', el retraso y la involución. Instituciones como los museos y las escuelas a menudo son visualizadas como un objeto estable o derivado de una línea continua de progreso.

\section{Memoria e historia, política e ideología}

La experiencia en un museo, particularmente un museo escolar, articula tres dimensiones de abordar el pasado. Por un lado, las memorias individuales del que lo visita; por otro, la 0 las memorias colectivas y, por último, la mirada histórica. Sólo es posible separar analíticamente las dos primeras.

De la primera, dijimos que funciona como 'obstáculo epistemológico'. En este caso, las memorias individuales son encaradas como las interpretaciones que cada actor social da a su vivencia. Son memorias personales construidas en contextos más amplios. En el Museo hemos observado que la mayoría de los adultos que lo visitan recurren a 


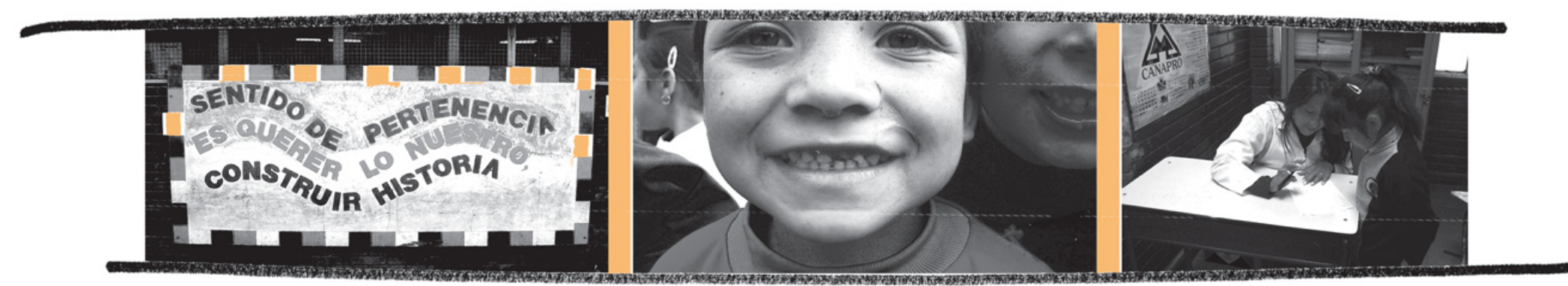

una memoria selectiva fijada en la 'nostalgia'. En algunos, se ha producido un borramiento de experiencias no gratificantes de su paso por la escuela, mientras que una minoría ha fijado sus memorias en el 'rechazo'; por lo general, son adultos relacionados con el mundo del arte. Por último, están aquellos que se presentan con una conciencia crítica, expresada por la ausencia de fijación en la nostalgia o el rechazo y por la disposición a inquirir, pedir explicaciones y realizar hipótesis durante la visita.

Respecto de la memoria colectiva, Tzevan Todorov (1998) cuestiona la oposición simple entre memoria y olvido. La dinámica propia de la memoria supone una selección de los hechos ya pasados estableciendo un compromiso entre la preservación y el borramiento. En este sentido, distingue entre memoria 'literal' que se refiere a una recuperación de acontecimientos como hechos singulares y mantienen continuidad sobre el presente, y la memoria 'ejemplar', que se sitúa más allá del acontecimiento sin negar su singularidad, pero incluyéndolo en una categoría general. Esta última es la condición de una dimensión pública de la memoria y es la que permitiría con- vertir el pasado en 'lección'; es decir, en principio de acción en el presente. Sin embargo, deja de lado los problemas de la formación de la memoria, "[...] es decir, los materiales, las formas y los marcos de la fijación y evocación de representaciones del pasado" (Vezzetti, 2002:32). Entendemos, como Vezzetti, que la memoria colectiva es una práctica social que requiere de materiales, de instrumentos y de soportes como ceremonias, libros, films, monumentos, lugares, etc. Por ello, pensamos que el Museo es un espacio que puede ayudar tanto a reproducir como a construir memorias colectivas, siempre que relativicemos su alcance y comprendamos sus límites.

Pensamos que 'la memoria', ya sea individual o social, se 'construye' selectivamente y este es un proceso histórico, contextulizado, a la vez que objetivo y subjetivo. En ese sentido, el Museo realiza su exposición desde una mirada histórica que, como hemos planteado, se enmarca en lo que denominamos 'historia social de la educación'.

Lo que elegimos para exponer en un Museo, la forma de exponerlo, lo que se deja de lado y lo que se silencia, supone una postura epistemológica e ideológica. Formamos parte de lo que Williams (1980) ha identificado como 'tradición selectiva'; esto es, de aquellos que muestran una versión intencionalmente selectiva de un pasado configurativo y de un presente preconfigurado que resulta poderosamente operativo dentro del proceso de definición e iden- 
tificación cultural y social. El Museo, como otras instituciones formales, tiene una profunda influencia sobre el proceso social activo y, aunque tiene una 'autonomía relativa' respecto del Estado o de la burocracia, reconoce que no puede escapar a su influencia.

Por lo expuesto, los significados que se plasman en la muestra implican un compromiso político que se asume no como rastro único e incuestionable, sino como pasado a ser leído y con el cual los visitantes no necesariamente van a estar de acuerdo. La muestra establece relaciones sociales entre quienes lo visitan y la institución, que tienen connotaciones pedagógico-políticas.

\section{El tiempo y la memoria}

En los espacios de un museo -salvo que cuenten con multimedia y otras ayudas tecnológicas-, presentan una velocidad de tiempo diferente. A través de las nuevas tecnologías de la información, los tiempos se han acortado de manera que pocas veces alcanzamos a 'digerir' las novedades que día a día surgen. Una computadora es para los chicos y para algunos adultos, un objeto como la heladera o el televisor, cuando hasta hace poco era objeto de veneración. "El mundo es hipersemiótico en la medida en que hay más signos de cosas, más signos de signos", afirma Beatriz Sarlo (2003). Pero no solo hay más imágenes, la velocidad con que suceden unas a otras ha aumentado. La percepción del tiempo ha cambiado. Esta aceleración ha modificado la memoria individual y colectiva produciendo fragilidad y, paradójicamente, despertando nuevos deseos de recuperar (en el sentido de construir) recuerdos.

¿Qué debe hacer el Museo? ¿Sucumbir a la era de la imagen y la tecnología, a la era de la velocidad? ¿Oponerse y rechazar cualquier multimedia mante- niendo el esquema de un tiempo anterior? ¿Lograr un equilibrio entre uno y otro? La mayoría estará de acuerdo con la última opción, pero sin duda es la más difícil, pues, ¿quién establece el equilibrio justo? Escapar a una concepción de tiempo que evidentemente ha cambiado o está cambiando es imposible. Pero el sometimiento sin una visión crítica sobre el mismo es imperdonable.

Todo aquello que pueda ser utilizado en beneficio de una mayor participación de los visitantes a los museos debe aprovecharse. Por ejemplo, los videos sobre historias de vida, los films relacionados con la historia de la educación, así como libros, documentos y fotografías que no pueden ser manipulados deben estar a disposición en una PC o en un sistema apropiado para su uso. Pero la falta de estos medios no nos debe preocupar. Las personas continúan realizando experiencias significativas con o sin ellos. Nuestra preocupación debe centrarse en que cada espacio del Museo provoque la memoria del visitante para que interpele y reflexione.

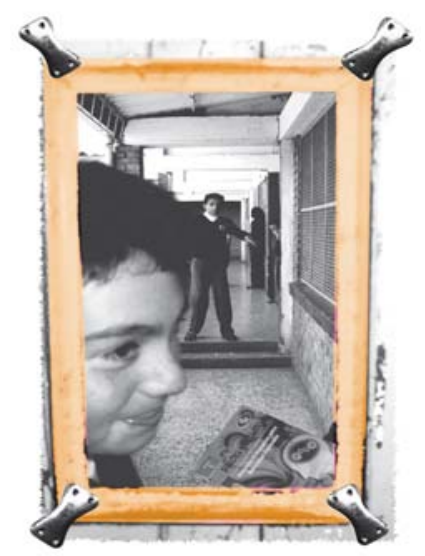




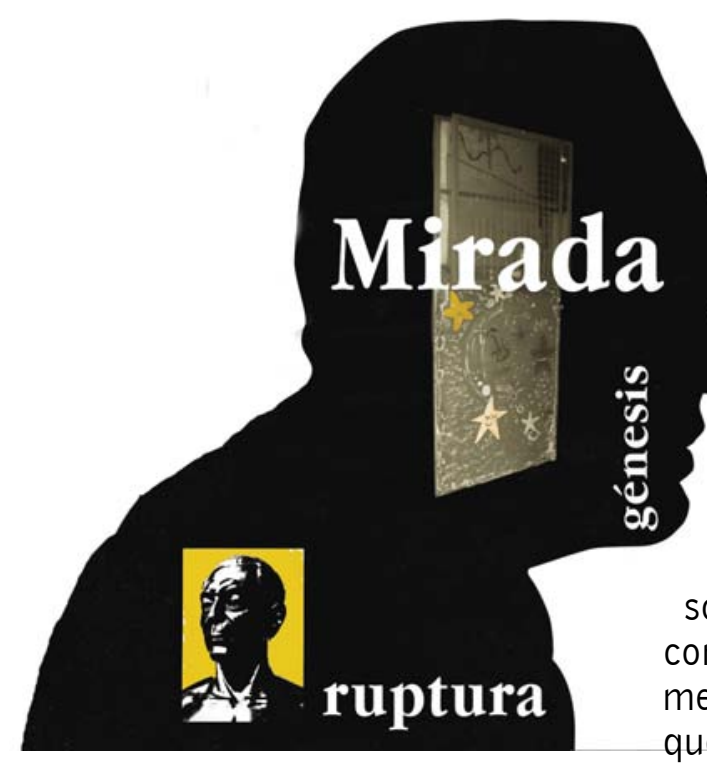

\section{Construcción temporal}

Otro problema que se presenta es el de la construcción temporal de la muestra. Los objetos y las prácticas en la historia de la educación denotan, en algunos casos, continuidad durante largos períodos y, en otros, cambios o rupturas que propician lecturas en períodos de corta duración. Por otro lado, hay que tener en cuenta que la esfera educativa suele proceder con una inercia propia que no siempre acompaña cambios en otras esferas de la sociedad.

Por ello, la 'contextualización' entendida como aquello que enmarca ciertos objetos en un momento histórico determinado, se presenta como una seria dificultad. Otras veces la 'contextualización' no alcanza. En varios casos debemos rastrear las génesis de determinados objetos, prácticas o ideas para entender por qué continúan existiendo a pesar de no corresponder con los cambios tecnológicos, económicos, políticos y culturales.

Otro tema a tener en cuenta, y que suele ser muy extendido en el campo de los museos de la educación, es la circunscripción de las exposiciones a miradas sincrónicas que recortan un período determinado. El período al que más se recurre es el decimonónico anterior a los sistemas nacionales de educación o a la etapa en que comienzan. El riesgo de pararse solo en esta mirada (no desechamos su utilidad) como si fuera una fotografía instantánea de un momento puntual en el pasado, es creer o hacer creer que ese periodo transcurrió sin rupturas, lo que nos retrotrae al problema de la 'naturalización', y una opción interesante es mantener, simultáneamente, miradas sincrónicas y diacrónicas para dar cuenta de los cambios y de las permanencias.

Ejemplificamos lo expuesto mediante la presentación de dos espacios de la exposición:

\section{Aula normal del mil novecientos}

Democratización y disciplinamiento en la escuela pública y estatal

Esta es un aula típica de 1940-1950, aunque conserva elementos anteriores a este período. El objetivo es visualizar más las continuidades que las rupturas de una escuela que estuvo en vigencia en el país desde 1910 hasta 1960. La hemos Ilamado 'normal', hija de maestros normalizadores.

\section{Con olor a libros}

Una historia de las escenas de enseñanza de la lectura

Esta sección está representada en vitrinas y muestra la historia del libro de lectura en Argentina des- 
de 1880 hasta la actualidad. El propósito es mostrar mediante un medio, en este caso el libro, un periodo en la corta duración. Cada vitrina responde a un período histórico:

- Nace el Estado Nacional (1880-1920).

- De lo nacional al nacionalismo (1920-1952).

- El Justicialismo en los textos (1952- 1955).

- Comienzan los cambios (1970-1976).

- Tiempo de silencios (1976-1983).

- Retorno a la democracia (1983-200..).

Esto permitió objetivar el trabajo de investigación desarrollado en el marco del Proyecto HISTELEA (Historia de la lectura y la escritura en Argentina, del catecismo colonial a la 'Razón de mi vida', y el Proyecto HISTELEA II -1955 hasta la actualidad-) del equipo de Historia Social de la Educación de la Universidad Nacional de Luján.

\section{¿Qué hacer con los objetos?}

El museo recupera, colecciona, conserva, da a conocer y proyecta expresiones educativas y lingüísticas, objetos -útiles escolares, juegos, juguetes educativos y material didáctico- de niños y adolescentes, prácticas escolares oficiales y alternativas que ponen de manifiesto la variedad y riqueza del patrimonio educativo argentino. Esto nos enfrenta a otra problemática, la cuestión de los objetos y los contenidos.

La exposición exhibe objetos en relación con sus contenidos. Pero, ¿qué queremos decir con esto? Que cada uno de los objetos de la muestra está jerarquizados: es tan importante el cuaderno como la pluma o el libro. No interesa si este o aqual objeto fue utilizado por tal o cual persona. Nos interesa rescatar los objetos por los ejes articuladores que den cuenta de ideas o de prácticas escolares. Por ejemplo, en el Aula normal, el objetivo es visualizar más las continuidades que las rupturas. Allí cada uno de los objetos expuestos refiere a los principales conceptos que conforman el guión narrativo: positivismo, espiritualismo, normalismo, regularización, democratización, nacionalismo, detallismo didáctico, aula global, poder concentrado del docente, higienismo, uniformidad, enciclopedismo, Estado educador.

En tanto que dispositivos específicos de las prácticas, tratamos de rescatar las particularidades de algunos objetos por sus fines de uso, por sus limitaciones 0 por sus características tecnológicas. Tal es el caso de la historia del cuaderno, de la pluma o de la pizarrita, que se presentan en 'hojas genealógicas' a disposición de los visitantes o en Internet.

\section{Síntesis y complejidad}

El Museo y las publicaciones que allí se realizan, son espacios de difusión para un público ampliado. Nuestra intención es presentar la experiencia en diferentes niveles de abordaje, de modo que los visitantes personalicen la información expuesta y elijan la complejidad y la profundidad de la información que desean. Cada visitante expresa modos

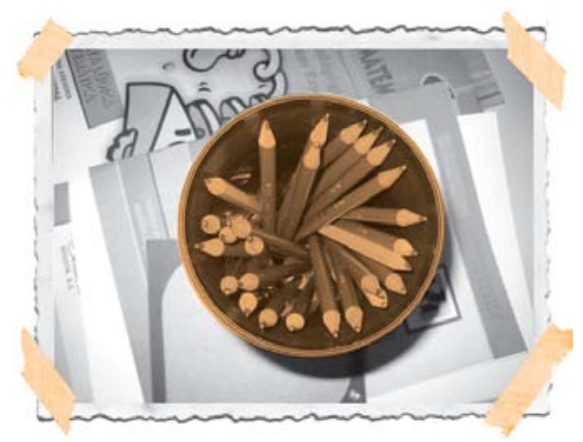


distintos de aprender, niveles y estilos: respuestas emotivas o vinculadas con la observación de otros compañeros, respuestas experimentales 0 respuestas conceptuales. Creemos que no debemos centrarnos en solo dar información, sino en provocar la interacción por medio de 'conversaciones elaboradas' (Leinhardt: 2000) como el proceso más significativo en la experiencia del museo.

Por 'conversación elaborada' nos referimos a un tipo particular de hablar que ocurre en un grupo o en un individuo durante la visita a un museo. Este tipo de conversación se enfoca en la naturaleza del significado y en la experiencia del museo, y permite reflexionar acerca de los procesos de negociación cultural entre el museo y el visitante. La conversación es un proceso disfrutable, compartido, es el lugar donde aparece lo nuevo y lo desconocido; donde las ideas se expresan para ser compartidas con otros, de un modo que permita a los miembros del grupo construir conocimiento.

Para propiciar estas conversaciones, diseñamos cédulas informativas, enunciativas y de actividades; guiones de visita: a. primero y segundo ciclo de la escuela primaria, b. tercer ciclo de primaria y escuela secundaria, c. profesores, alumnos de profesorados y universidades, y d. público en general. También elaboramos materiales informativos como hojas genealógicas y publicaciones. Estas alternativas están en función de reforzar en cada rincón los criterios museológicos de objetos y de ideas: las conexiones significativas, el intercambio generacional

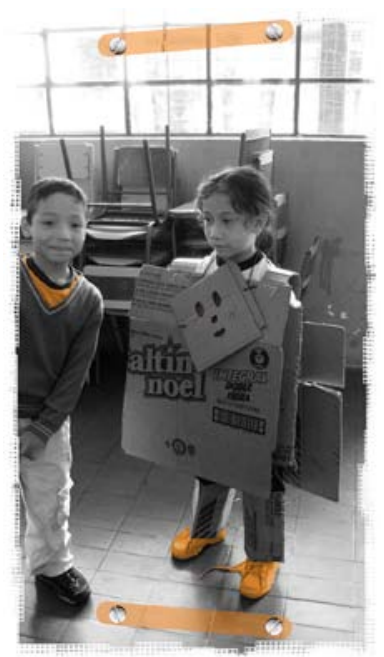

y los niveles de abordaje para que cada visitante sea "su propio editor seleccionar y compaginar los objetos que le interesan" (Pérez Gollán y Dujovne: 2001).

Ahora bien, sea cual fuere el soporte elegido, hay una característica que se mantiene: la necesidad de la síntesis. Pero aquí se presenta otro problema ya que esta modalidad le resta complejidad al fenómeno, limita la posibilidad de un desarrollo profundo y de una buena articulación, sobre todo con el contexto de producción y apropiación del mismo. Hasta el momento, más allá de la intervención del guía del Museo (que amplía, complejiza y contextualiza los relatos), no hemos encontrado respuestas que abonen a su solución.

\section{Capacitación profesional}

Los guías participan de manera explicativa para que la interacción de los visitantes con el mensaje que transmite el museo y la información que estos intercambian entre sí, tenga sentido para ellos. Aunque el Museo presenta la información de un modo didáctico y para que se fomente la investigación en el 
visitante, las conversaciones que se desarrollan nos dan la idea que los visitantes están 'ocupados', 'entretenidos'. El compromiso de explicar es una medida del grado en el cual los visitantes se involucran en oportunidades explicativas particulares.

Los beneficios del trabajo libre de pequeños grupos con un adulto no directivo, que da información cuando es necesario, que inserta preguntas para propiciar el diálogo, que lee información cuando le fue requerida, que inserta preguntas foco como, ipor qué les parece que los alumnos tenían la letra tan parecida?; promueve entre los visitantes:

- Interacciones que desempeñan un rol importante en el aprendizaje.

- Ideas novedosas derivadas de sus necesidades, de la información y de la experiencia obtenida durante la visita.

- Profundización del discurso oral con referencia al tema en cuestión.

- Establecer vínculos entre las actividades de la escuela y las del Museo, entre los objetos y modelos, entre sus experiencias y futuras actividades, entre las experiencias y su interpretación.

Optar por esta modalidad implica que los encargados de guiar las vistas sean profesionales en dos temas específicos: en el aprendizaje en el Museo, y en historia de la educación. Este proceso requiere capacitación continua y de estabilidad en la conformación de los equipos. Para ello, desde el año

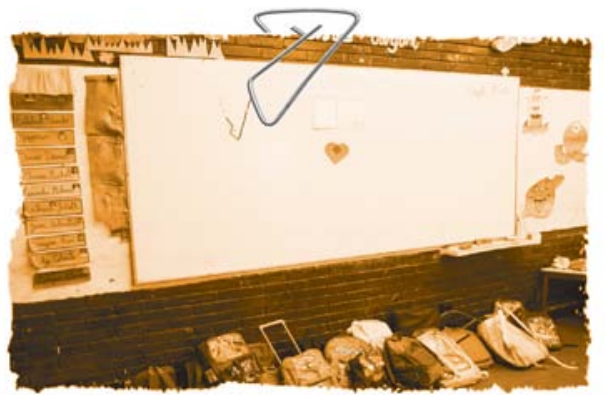

pasado establecimos seminarios que se desarrollan mensualmente.

\section{La evaluación}

Los procedimientos de evaluación museal intentan garantizar las mejores condiciones de relación entre quienes conciben una exposición y los efectos que esta produce en los visitantes. Los siguientes indicadores evalúan el alcance individual, espacial y social del Museo:

- Expectativas de los visitantes.

- Iniciativas producidas a partir de la visita.

- Interrogantes surgidos durante la visita.

- Participación de los visitantes.

- Diálogos surgidos entre visitantes.

- Demandas surgidas durante y a posteriori de la visita.

- Actividades desarrolladas a posteriori de la visita.

Para ello, utilizamos distintas herramientas:

- Publicación de los AVC, cuadernillos que informan sobre la visita y recogen las expectativas de los visitantes.

- Redacción de la Ruta de exploración por parte de las guías cuandow se producen las visitas, registrando las conductas de los mismos.

- Registro del Libro de visitantes, archivo de pizarrones y cuadernos, que se encuentran en el museo, donde los visitantes pueden escribir.

- Hoja de evaluación, para ser completada por los visitantes. 


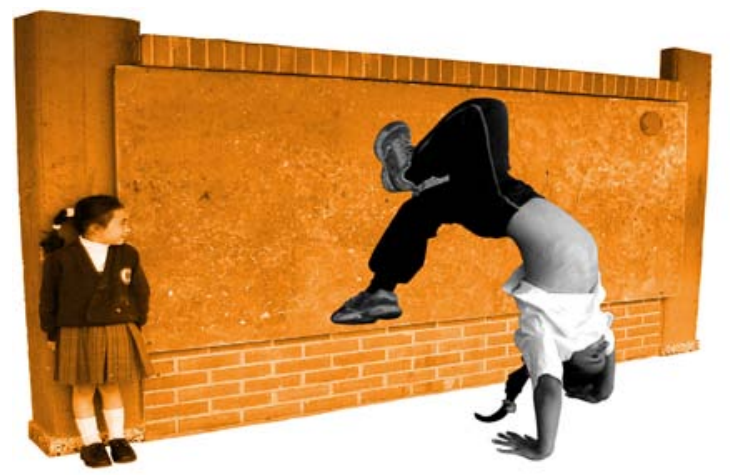

- Redacción de la Posdata contactando a las instituciones a posteriori de la visita.

Para ejemplificar uno de los mecanismos de evaluación, observemos el caso del Libro de visitantes. De la lectura de los mensajes escritos por los visitantes, construimos algunas categorías que se articulan con los propósitos y objetivos del Museo:

- Construir memorias para construir futuros.

- Escuelas construyendo naciones.

- Relatos intergeneracionales. El pasaje de relato.

- La identificación de objetos propios que pasan a la visibilidad pública.

- Miradas desde la nostalgia.

- Miradas desde la crítica.

- Ser partícipe y no espectador. Cruce de narrativas.

- El Museo no termina en la muestra, se puede extender.

Trabajar con estos conceptos permite volver a ver el guión narrativo para fortalecerlo y buscar nuevos dispositivos para ello. Por otro lado, las producciones de los alumnos de diferentes niveles educativos, aunque no he- mos llegado a sistematizar su recolección, aporta ideas creativas para seguir pensando el Museo.

\section{..De cómo me utilizó la educación}

Muchos pensarán que estoy presente en casi todos los ámbitos de la educación por arte de magia. Pero no. No fue así. Fue un largo proceso que empezó allá por 1880. iQué tiempos aquellos!

Eran los tiempos de los primeros libros de texto, en su totalidad libros extranjeros, con tapas duras, para ayudar al "buen leer". Y así aparecí, acompañando esos textos. Un libro muy importante de esa época

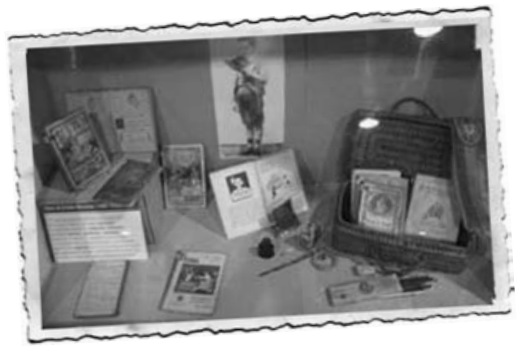

fue El Nene. Fueron años donde en Argentina no había editoriales, sino que estaba el amigo librero. Hasta que un señor llamado Ángel Estrada tuvo la idea de comenzar a editar libros, con la colaboración de escritores nacionales. Era la época que se necesitaba identidad nacional, homogeneidad, noción de pertenencia al terruño. 
En 1930 se produce el primer golpe de estado en Argentina. Con este acontecimiento político, se produce en lo social, cultural y educativo un fuerte sentimiento nacionalista. Es ahí donde empiezo a tener

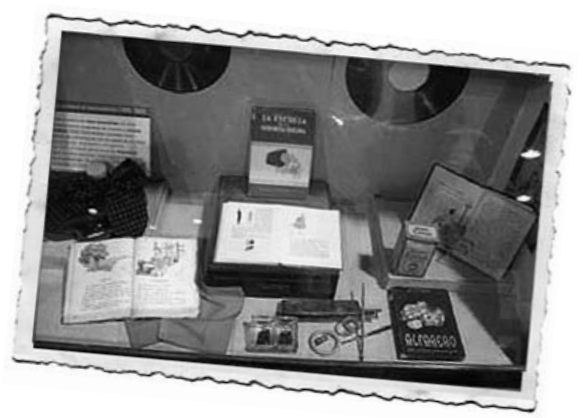

más importancia dentro de la educación, donde tengo más lugar en los libros, en detrimento del texto.

En 1941 aparece un Reglamento de cómo tiene que ser un libro de texto.

Luego, en la etapa peronista, soy utilizada para hablar de las bondades de Perón, o la importante figu-

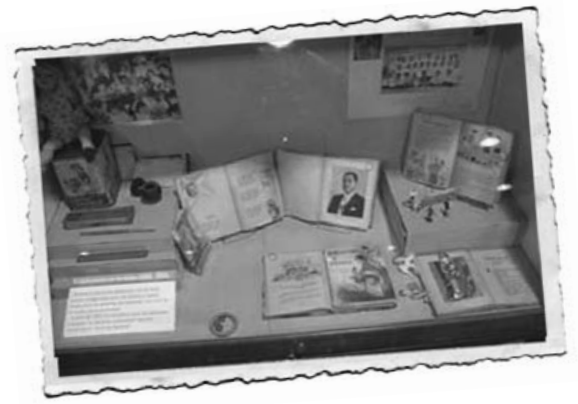

ra de Eva Perón frente a los niños, frente al deporte, frente a la sociedad. En casi diez años aparezco enalteciendo la figura de un proyecto político, que cae en 1955. Al ser proscrito todo lo que esté relacionado con el peronismo, retiran todos los libros peronistas, y por ende todo soporte educativo donde yo aparezca. Eso sucedió en septiembre del 55. La pregunta es: ¿qué hicieron las maestras conmigo cada vez que me veían relacionada con el peronismo? Y bueno, había que terminar el ciclo lectivo como sea. Así que aplicaron "tijera". Lugar donde aparecía vinculada al peronismo, era sacada del libro de texto.

Fue cuando volví a ser como era en el 41. Fue raro pero fue así. Volví para representar, entre otras cosas, a la mujer cocinando, cosiendo, y no tanto a la mujer frente a una Singer, o con una tiza frente a un aula.

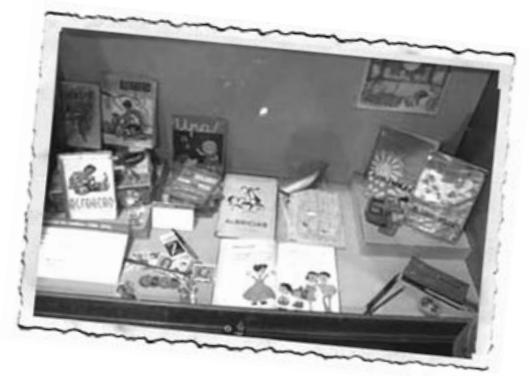

De 1956 a 1976 se produce un lento proceso de borramiento de la etapa del "mandatario depuesto", como así también de la "señora del tirano" para transformarme lentamente en algo abstracto. Fue una época en la que -a diferencia de etapas anteriores- no representé a ningún sujeto de este suelo argentino. Nada de trabajadores, de madres, de maestros y maestras. No me relacionaron en esta etapa con nada que se pareciera a lo argentino. Sin embargo en esta etapa se empezó a abandonar la idea de libro como "libro de lectura". En algunos por ejemplo se incorporó el conflicto, como en "Dulce de Leche". También una escritora -María Elena Walsh-plantea la idea de una mujer periodista, lejos de aquella idea de mujer ama de casa, madre, costurera o maes- 
tra. En estos años está en auge el movimiento feminista, la liberación sexual, la famosa "pastillita", y la defensa por las minorías. Es llamativo que jamás hasta ahora en la educación argentina, aparecí representando a una mujer embarazada. Por otro lado tampoco había demasiado despliegue editorial, producto de los serios problemas económicos del tercer gobierno peronista, hasta la caída de Isabel.

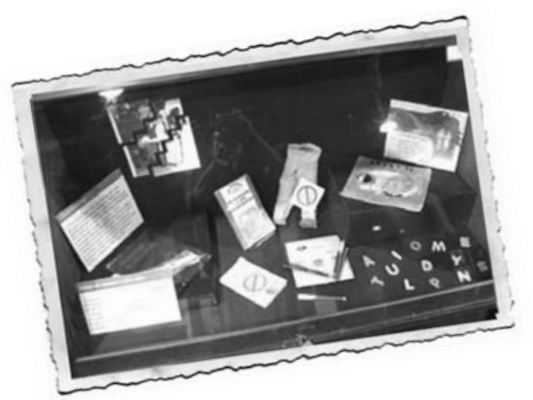

De 1976 a 1983 me prohíben en todo aquello que esté relacionado, por ejemplo, al Principito. Fue curioso porque en esta etapa no se registran hechos puntuales de censura de libros por parte de la dictadura. Son las mismas editoriales las que directamente ejercen una suerte de autocensura. En esta etapa sale un libro donde expresamente se plantea cómo debe ser la educación, y qué cosas no se pueden dejar librado al azar, al libre pensamiento. Es la época donde me usan para representar a un buen general (Galtieri presidente de facto) dándole un beso a una alumna pulcramente vestida.

Con el advenimiento de la democracia, en 1983, aparezco nuevamente casi en un nivel de igualdad con respecto al texto.

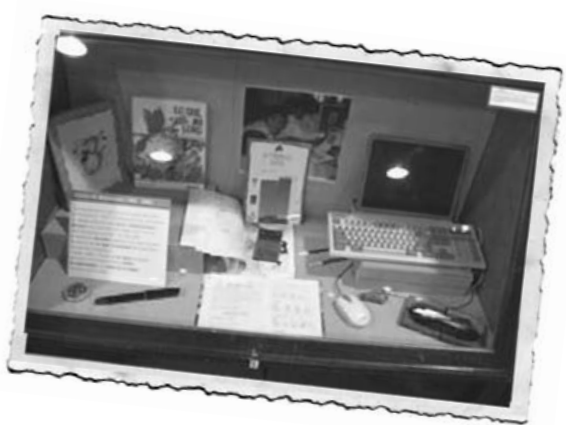

El libro ahora es ahora usado para lectoescritura. No sólo acompaño al texto para que los alumnos aprendan a leer, sino que también para que me pinten, o para que me ordenen en rompecabezas.

Como verán, en tanto imagen, fui utilizada de variadas maneras en Argentina, unas veces con un lugar importante y otras veces no tanto. Algunas para alentar procesos políticos, y otras veces para borrarlo. Siempre fui utilizada dentro de cada proyecto educativo en el país. Me pregunto muchas veces si lo hicieron concientes de ello, o no.

\section{Me pregunto finalmente: como imagen, dentro de la educación, ¿valdré más que mil palabras?}

\section{Raúl Montes}

Alumno de la carrera de Comunicación, UBA. - e y c 
Alderoqui, S. "Museos y escuelas: una sociedad que fructifica", En Museolúdica, Universidad Nacional de Colombia, vol. 3. № 5, Bogotá: 2000.

---------- y Linares M.C. "El libro de visitantes del Museo de las Escuelas: un diálogo entre narrativas", en: Enseñanza de las ciencias sociales, № 4, Madrid: 2005.

Alderoqui Pinus, D., "Look Again! Planning an exhibition with social interaction in mind", en: Journal of Museum Education, vol. 1-2, 2000.

Falk, J. y Dierking, L. The museum experience. Washington: Whalesback Books, 1992.

Karol, Mariana. "La transmisión: entre el olvido y el recuerdo, entre el pasado y el futuro", en: Una ética en el trabajo con niños y jóvenes. La habilitación de la oportunidad, Buenos Aires: Novedades Educativas - Cem, 2004.

Leinhardt, G. y Crowley, K. The museum learning collaborative. http:||museumlearning. com|default.html

Pérez Gollán, José Antonio y Dujovne Marta. "De lo hegemónico a lo plural: un museo universitario de antropología”, en: Entrepasados, Revista de Historia, año X № $20 \mid 21$ pp. 197-208. Buenos Aires: [...], 2002

Sarlo, Beatriz. Tiempo presente. Notas sobre el cambio de una cultura. Buenos Aires: Siglo Veintiuno, 2003.

Vezzetti, Hugo. Pasado y presente, guerra, dictadura y sociedad en la Argentina. Buenos Aires : Siglo XXI, 2002. 